\title{
Lifetime Assessment Method using Multiple-Stress Acceleration Aging for Flexible Cable of Portable Electric Machines
}

\author{
Jeongtae Kim*, Ji-Sub Yoon* and Sang-Won Choi ${ }^{\dagger}$
}

\begin{abstract}
In this study, in order to analyze the lifetime for flexible cables used in portable electric machines, artificial accelerating aging was carried out for VCT(Vinyl Cab-Tire) cables in consideration of thermal, mechanical and electrical multiple-stresses. Accelerated aging factors were calculated with aging temperatures based on the Arrhenius relationship. Through Weibull statistical analysis in the $\mathrm{AC}$ breakdown voltages for aged cables after low-temperature mechanical tests, it was analyzed that $\mathrm{AC}$ breakdown voltages were proportional to the elongation rates and $19 \mathrm{kV}$ of the scale parameter in Weibull analysis was suggested as limit value of lifetime. Using this criterion, it was deduced that the lifetimes with thermal and mechanical multiple-stresses for $70^{\circ} \mathrm{C}, 50^{\circ} \mathrm{C}$ and $40^{\circ} \mathrm{C}$ continuous operation were calculated to be 3.3 years, 9.9 years and 15.7 years respectively. Based on these analysis procedure, it is possible to suggest the lifetime assessment technique with multiplestresses for low voltage cables.
\end{abstract}

Keywords: Lifetime, Low voltage flexible cable, Thermal and mechanical stresses, AC breakdown

\section{Introduction}

For portable electric machines used for the construction site, the main cause of electric shock accidents would be insulation damages of cables [1], which results from the loss of insulation performance and carelessness of management supervision. In particular, cables in potable facilities such as electric motors, welding machines, temporary electric supplies etc. are always faced with mechanical damages and degradation in insulation layers due to problems in various construction work types and methods and harsh working environment. But, research on insulation degradation and lifetime assessment for lowvoltage cables has not been established enough compared with high voltage cables. [2,3]

VCT(Vinyl Cab-Tire) cables are widely used in portable electric machines in the construction site because of flexibility and cheapness of PVC insulation and sheath. In comparison with PNCT(EPR insulation Chloroprene sheath Cab-Tire) cables and WCT(Rubber insulation Rubber sheath Cab-Tire) cables, there would be high probability of electric shocks and fire accidents caused by damage of insulating layer and sheath in case of VCT cables owing to decreased flexibility for long period usage or severe mechanical impacts. [4,5] However, the life assessment and the replacement cycle according to degradation for VCT cables have never been reported.

Therefore, in this study, the lifetime characteristics of

$\dagger$ Corresponding Author: Occupational Safety Research Bureau, Occupational Safety and Health Research Institute, Korea. (swchoi@kosha.net)

* Dept. of Electrical Engineering, Daejin University, Korea. (jtkim@daejin.ac.kr, invictusss@naver.com)

Received: December 10, 2015; Accepted: May 20, 2016
VCT cables were focused on. The degradation evaluation and the lifetime assessment for the thermally aged cables were carried out through mechanical stresses and electrical breakdown experiments for the VCT cables.

\section{Experimental Methods}

\subsection{Thermal degradation method}

In general, thermal degradation for the polymer insulation material is known to be followed with Arrhenius relationship equation. [6] Thus, before starting the thermal aging process in this study, it is possible to estimate lifetime roughly and to decide accelerated aging temperatures. In the preliminary experiment at $150^{\circ} \mathrm{C}$, it was found out that PVC insulation was rapidly degraded. Therefore, aging temperatures of $110^{\circ} \mathrm{C}, 130^{\circ} \mathrm{C}$ and $140^{\circ} \mathrm{C}$ were selected in considering to ensure proper degradation mechanism.

Thermal accelerated aging method was adopted in reference to KS C IEC 60811-1-2, 8. 'Method of thermal aging'. [7] Specimens were installed vertically inside an oven as the state of the products including conductor, insulation and sheath. Each specimen was placed each other over $20 \mathrm{~mm}$ in consideration of air circulation.

\subsection{Method for mechanical stress application}

The mechanical degradation during the use of VCT cables is generally considered as trampled, pressed, bent and so on. However, it was not possible to simulate the mechanical degradation with regard to the lifetime quantitatively. Therefore, in this study two methods were 
adopted for the lifetime evaluation using the biggest mechanical stress in the KS C IEC 60502-1 and KS C IEC 60811-1 standard.

\subsubsection{Low-temperature impact test}

After cooling the specimen as a finished product during more than 16 hours at low-temperature of $-15^{\circ} \mathrm{C}$, the hammer of $500 \mathrm{~g}$ was dropped from $100 \mathrm{~mm}$ height. Damage by the impact was investigated with bare eyes.

\subsubsection{Low-temperature bending test}

After cooling the specimen as a state of an insulation with conductor or a finished product during more than 16 hours at low-temperature of $-15^{\circ} \mathrm{C}$, wind the specimen to a cylinder which has a diameter of 4 5 times specimen diameter up to maximum 10 times with a speed of 1 cycle per second. Damage by the bending was investigated with bare eyes.

\subsection{Electrical breakdown method}

Insulation breakdown voltage was measured with submergence test according to KS IEC 60811-1 standard. After extracting conductor strands including insulator among the VCT cables having thermal degradation and mechanical stress, AC voltage was applied to the conductor of the specimen immersed with water.

AC voltage was raised up with the speed of approximately $0.1 \mathrm{kV}$ per second until the insulation breakdown occurred. After experiment for at least 10 specimens per each degradation condition, scale parameters were obtained by using Weibull statistics.

\subsection{Elongation rates measurement}

The measurement of elongation rates was carried out for tubular insulation specimens removing completely conductor and sheath after thermal accelerated aging. A specimen with length of $80 \mathrm{~mm}$ to the tensile strength tester was installed and tested. The elongation rate was calculated with the elongated length until the sample had broken in gauge of $20 \mathrm{~mm}$ section. The median value of three or more specimens except the maximum and minimum value among at least five specific data was obtained as representative value.

After measuring the elongation rate of the aged specimens, the minimum limit less than $150 \%$ elongation rate in the VCT cables according to KS C IEC 60502-1 standard was adopted as the life assessment guideline. Using this limit, expected lifetimes were calculated for various temperatures. The elongation rate $\epsilon_{t}(t)$ is defined with the following equation.[8]

$$
\epsilon_{t}(t)=\frac{\text { Extended length }- \text { Gauge length }}{\text { Gauge length }} \times 100 \%
$$

\section{Lifetime Analysis using Elongation Rates for the Thermal Degradation}

The molecular weight is generally decreased in polymer materials during thermal degradation, because chains of molecules are broken, which leads to the reduction of physical characteristics such as elongation rate and tensile strength. It is known that tensile strength in polymeric materials decreases exponentially with time at constant temperature. [9]

$$
\epsilon_{t}(t)=\epsilon_{t_{0}} e^{-B_{\epsilon_{t}}(T) t}
$$

Here, $\epsilon_{t}(t)$ is the elongation rate in time $t$. And, $\epsilon_{t_{n}}$ is the initial elongation rate, $B_{\epsilon_{t}}(t)$ is a coefficient of degradation condition and temperature, and it is assumed to follow the Arrhenius equation as follows;

$$
B_{\in_{t}}(T)=B e^{\frac{E_{a}}{R T}}
$$

Here, $E_{a}$ is activation energy and approximately 92.16 $[\mathrm{kJ} / \mathrm{mol}]$ in the case of PVC insulation of cables. [10] $T$ is the temperature $[\mathrm{K}]$ of the specimen, $R$ is the gas constant $(8.314[\mathrm{~J} / \mathrm{mol}])$, and $B$ is the environmental factor $\left[h^{-1}\right]$ which give an effect on the degradation of the specimen such as water, oxygen, acid, etc.

Fig. 1 shows the change of elongation rate with aging time for various aging temperatures. Elongation rates are reduced exponentially with time and more severely with the aging temperature from same initial value.

The lifetime of the VCT cables can be obtained using data of elongation rates as shown in Fig. 1 as follows;

1) Derive trend formula and degradation coefficient $B_{\epsilon_{t}}(T)$ with aging temperature

$$
\begin{aligned}
& \epsilon_{t}(t)_{110^{\circ} \mathrm{C}}=219.9 e^{-0.001846 t} \\
& \epsilon_{t}(t)_{130^{\circ} \mathrm{C}}=219.9 e^{-0.011087 t} \\
& \epsilon_{t}(t)_{140^{\circ} \mathrm{C}}=219.9 e^{-0.022404 t}
\end{aligned}
$$

2) Calculate Arrhenius relationship coefficient $E_{a} / R T$ and environmental factor $B$ with aging temperature

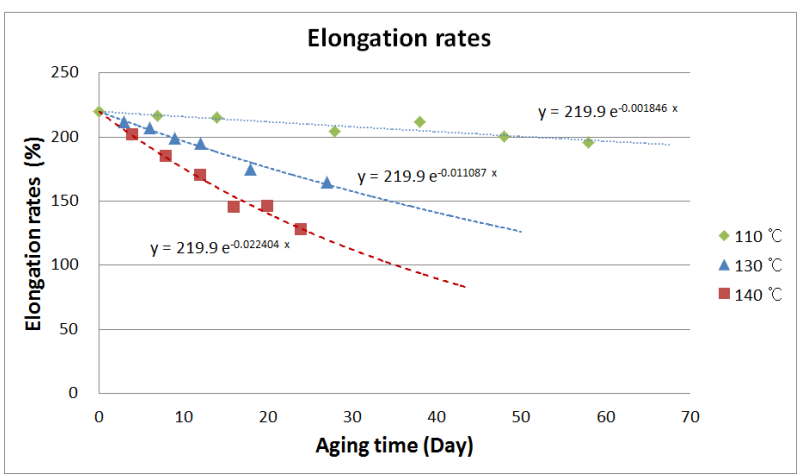

Fig. 1. Elongation rates with the thermal degradation 


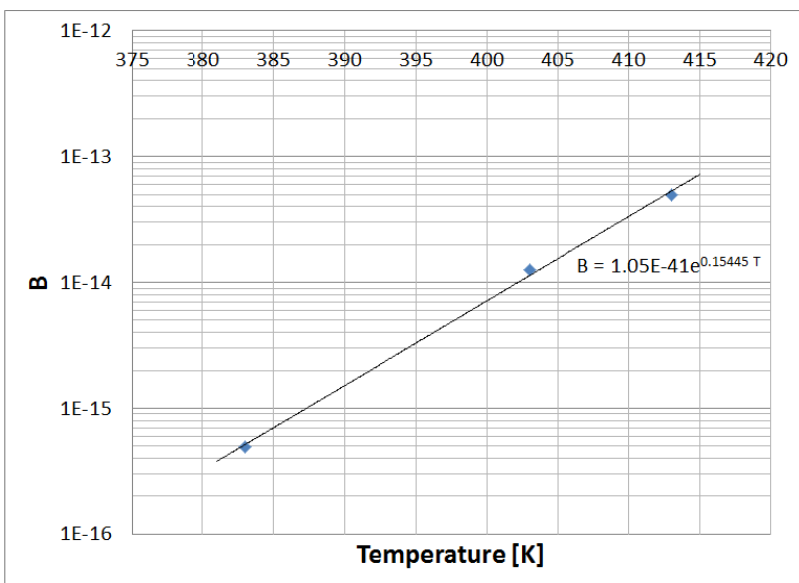

Fig. 2. Trend formula for environmental factor $B$

Table 1. Calculations for accelerated aging factors and lifetime limits in equivalent operating years

\begin{tabular}{c|c|c|c|c|c}
\hline $\begin{array}{c}\mathrm{T} \\
{\left[{ }^{\circ} \mathrm{C}\right]}\end{array}$ & $\frac{E_{a}}{R T}$ & $B_{\epsilon_{t}}(T)$ & $\mathrm{B}$ & $\begin{array}{c}\text { Accel. } \\
\text { aging } \\
\text { factors }\end{array}$ & $\begin{array}{c}\text { Lifetime limit } \\
\text { in equivalent } \\
\text { operating years }\end{array}$ \\
\hline 140 & $4.53 \times 10^{11}$ & 0.022404 & $4.94 \times 10^{-14}$ & 193.9 & 17.1 days \\
\hline 130 & $8.82 \times 10^{11}$ & 0.011087 & $1.26 \times 10^{-14}$ & 96.0 & 34.5 days \\
\hline 110 & $3.71 \times 10^{12}$ & 0.001846 & $4.97 \times 10^{-16}$ & 16.0 & 207.2 days \\
\hline 70 & $1.08 \times 10^{14}$ & 0.0001155 & $1.06 \times 10^{-18}$ & 1.0 & 9.1 years \\
\hline 50 & $8.02 \times 10^{14}$ & 0.0000398 & $4.85 \times 10^{-20}$ & 0.337 & 26.9 years \\
\hline 40 & $2.40 \times 10^{15}$ & 0.0000249 & $1.04 \times 10^{-20}$ & 0.215 & 42.1 years \\
\hline
\end{tabular}

3) Derive trend formula for environmental factor $B$ as shown in Fig. 2

$$
B=1.05 \times 10^{-41} \cdot e^{0.15445 T}
$$

4) Calculate $\mathrm{B}$ and complete the lifetime formula at $70^{\circ} \mathrm{C}$ of maximum permissible temperature in VCT cables

$$
\epsilon_{t}(t)_{70^{\circ} \mathrm{C}}=219.9 e^{-0.000116 t}
$$

On the other hand, in the case of PVC materials according to the KS C IEC 60502-1, the elongation rate of $150 \%$ should be regarded as disqualification. Thus, this value can be considered as the criterion of lifetime limit. In other words, it is able to consider the lifetime limit at the point of less than the elongation rate of $150 \%$ by long-term degradation in use. Using this relationship eventually, calculations for accelerated aging factors and lifetimes in equivalent operating years could be made as shown in Table 1 . The lifetime in equivalent operating years at $70^{\circ} \mathrm{C}$ was calculated with approximately 9.1 years.

This result is generally quite low compared with asconsidered lifetime of $20 \sim 30$ years for VCT cables. The reason of this difference is due to the calculation under assumption of continuous operation at $70^{\circ} \mathrm{C}$. If the operation temperature of cables was considered as the actual case, it is expected to take longer lifetime than this

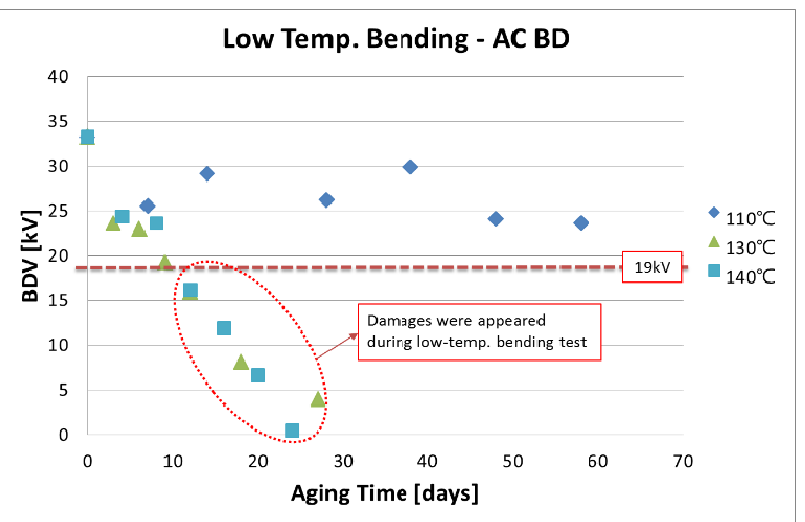

Fig. 3. AC breakdown voltage after low-temperature bending test with aging time

value. When considering the lower continuous operation temperature of cables, lifetimes can be obtained 26.9 years at $50^{\circ} \mathrm{C}$ and 42.1 years at $40^{\circ} \mathrm{C}$.

$$
\begin{aligned}
& \epsilon_{t}(t)_{50^{\circ} \mathrm{C}}=219.9 e^{-0.0000389 t} \\
& \epsilon_{t}(t)_{40^{\circ} \mathrm{C}}=219.9 e^{-0.0000249 t}
\end{aligned}
$$

\section{Analysis of AC Breakdown for Specimens with Thermal and Mechanical Multiple-stresses}

\subsection{AC breakdown voltage after low-temperature bending test}

Fig. 3 shows the result of AC breakdown experiments for thermally aged specimens after low-temperature bending test. In case of $110^{\circ} \mathrm{C}$ degradation, $\mathrm{AC}$ breakdown voltages were slightly decreased with aging time, but they showed more than $5 \mathrm{kV}$ and no physical damage occurred up to 58 days. But in the case of the degradation of $130^{\circ} \mathrm{C}$ and $140{ }^{\circ} \mathrm{C}$, damaged specimens in insulation began to appear during the low-temperature bending test after more than 10 days aging. In the submergence AC breakdown test, the damaged specimen during low temperature bending test showed $0 \mathrm{kV}$, because $\mathrm{AC}$ voltage could not be applied to the damaged specimen. Due to these damaged specimens for severe aging conditions, the AC breakdown voltage as the scale parameter of Weibull statistics showed less than $19 \mathrm{kV}$. Therefore, breakdown voltage of $19 \mathrm{kV}$ was considered as the lifetime limit through AC breakdown test of the specimen with thermal and mechanical multiplestresses. In between $130^{\circ} \mathrm{C}$ and $140^{\circ} \mathrm{C}$ degradation, there was no significant difference in AC breakdown voltage, which implies that mechanical damages were similar over a certain level of degradation.

\subsection{AC breakdown voltage after low-temperature impact test}

Fig. 4 shows the result of $\mathrm{AC}$ breakdown experiment for 


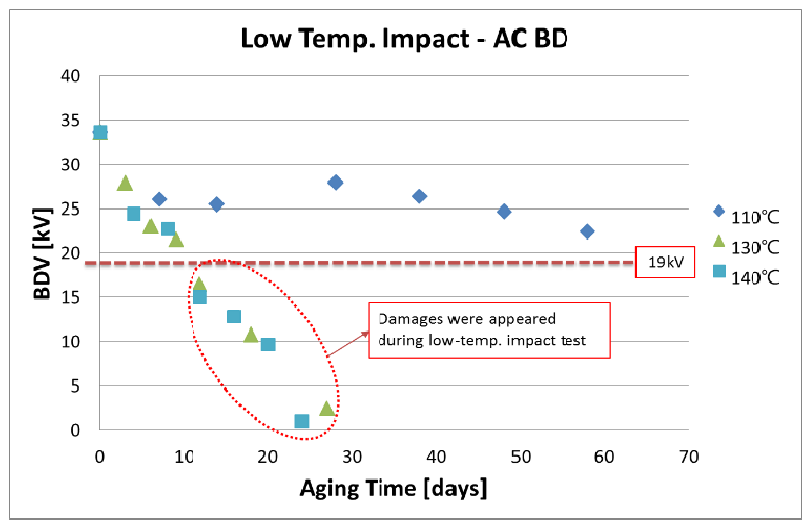

Fig. 4. AC breakdown voltage after low-temperature impact test with aging time

thermally aged specimens after low-temperature impact test. The result was almost the same as that of lowtemperature bending test. In the low-temperature impact test, less than $19 \mathrm{kV}$ of the scale parameter in Weibull statistics could be also considered as the lifetime limit, because mechanical damages occurred in the lowtemperature impact test for the specimens with the aging condition showing less than $19 \mathrm{kV}$ breakdown voltage value.

Thus, considered with above results, the mechanical stress in low-temperature bending test and low-temperature impact test could be regarded to be similar, which leads to the similar lifetime limit obtained from two experiments.

\section{Lifetime Assessment for VCT Cables}

\subsection{Correlation between AC breakdown voltages and elongation rates}

Fig. 5 shows the correlation between AC breakdown voltages after low-temperature bending test and elongation rates for the degraded specimens. Elongation rates and $\mathrm{AC}$ breakdown values were shown to be approximately proportional, which means that the reduction in physical properties leads to the reduction of dielectric strength. In Fig. 5, the shaded area above breakdown voltage of $19 \mathrm{kV}$ and elongation rate of $150 \%$ can be considered as an area of lifetime limit.

Similar with Fig. 5, Fig. 6 shows the correlation between AC breakdown voltage after testing low-temperature impact test and elongation rates. Since AC breakdown voltages after the low-temperature bending test and the impact test showed very close similarity to each other, elongation rates and $\mathrm{AC}$ breakdown voltages were generally shown to be proportional. Also, the shaded area above $19 \mathrm{kV}$ of AC breakdown voltage and $150 \%$ of elongation rates in Fig. 6 shows the same as those in Fig. 5, which seems to be considered as an area of lifetime limit.

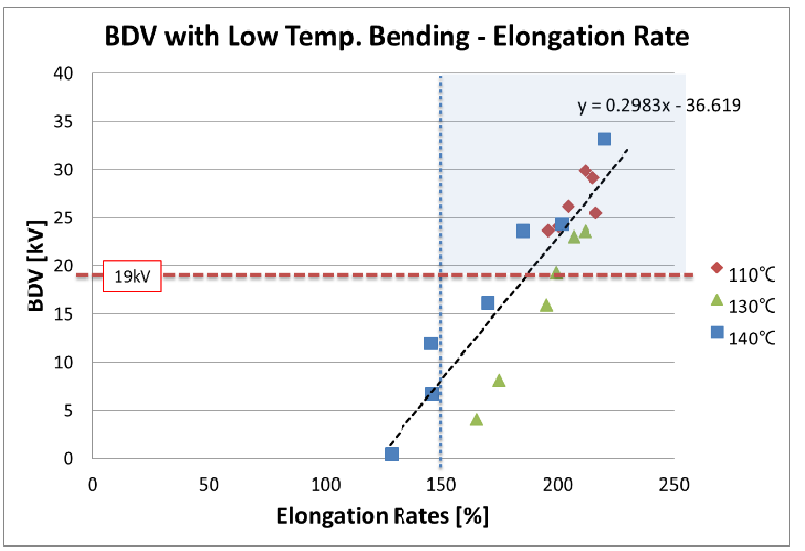

Fig. 5. Correlation between elongation rates and $\mathrm{AC}$ breakdown after low-temperature bending test

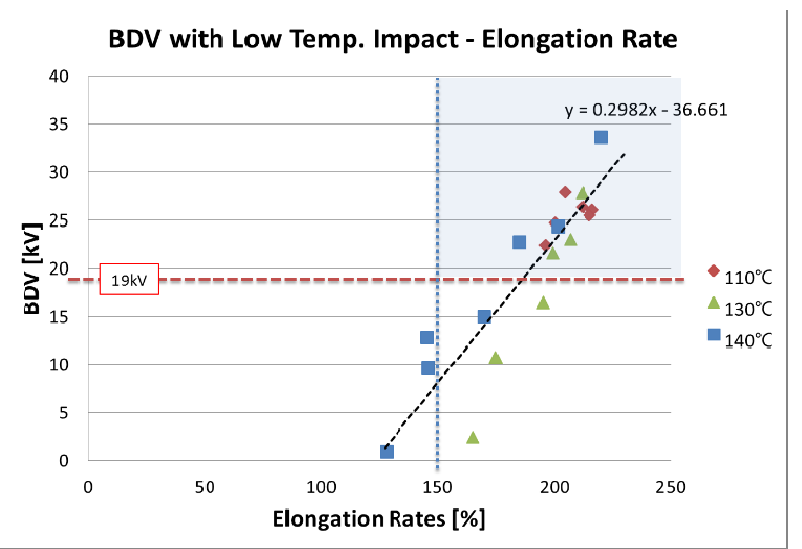

Fig. 6. Correlation between elongation rates and $\mathrm{AC}$ breakdown after low-temperature impact test

\subsection{Lifetime analysis in consideration of equivalent operating years}

As shown in Table 1, accelerated aging factors and lifetimes in equivalent operating years according to temperatures were analyzed using elongation rate data for aged PVC insulation of VCT cables. Moreover, AC breakdown voltages after low-temperature bending test or low-temperature impact test were measured and the correlation between AC breakdown voltage and elongation rate was obtained. In Fig. 7, the results of AC breakdown voltage voltages and elongation rates were rearranged according to the $70^{\circ} \mathrm{C}$ equivalent operating years in consideration of accelerated aging factors of $110^{\circ} \mathrm{C}, 130^{\circ} \mathrm{C}$ and $140^{\circ} \mathrm{C}$. In case of $\mathrm{AC}$ breakdown voltage voltages the ratio with elongation rate as shown in Fig. 5 and Fig. 6 were multiplied.

As shown in Fig. 7, AC breakdown voltage data were well fit to the trend line of elongation rates. As mentioned in Table 1, the lifetime limit for the elongation rates of $150 \%$ was 9.1 years with the continuous operation at $70^{\circ} \mathrm{C}$. However, the lifetime limit for $\mathrm{AC}$ breakdown voltage of 


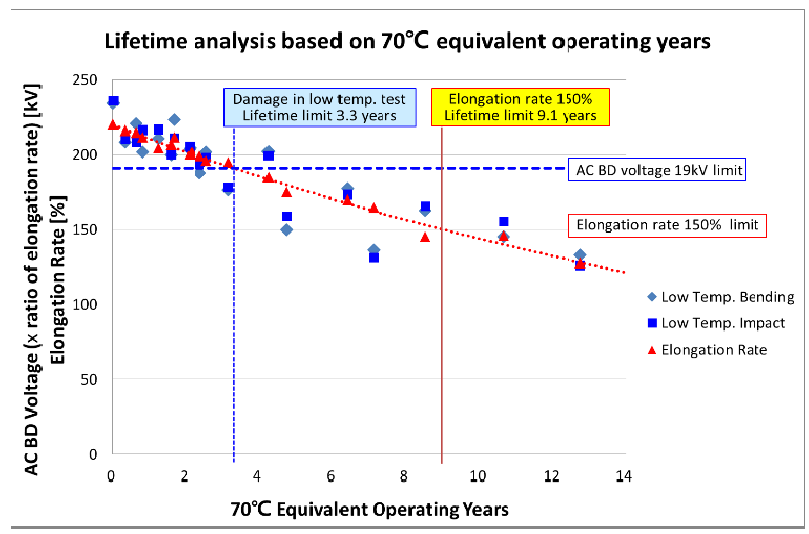

Fig. 7. Analysis of AC breakdown voltages and elongation rates based on $70^{\circ} \mathrm{C}$ equivalent operating years

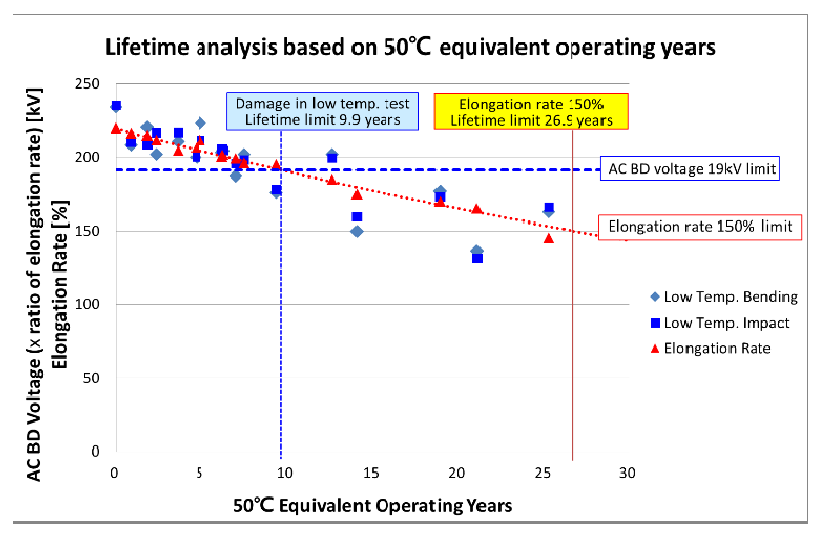

Fig. 8. Analysis of lifetime limit for $50^{\circ} \mathrm{C}$ equivalent operating years

$19 \mathrm{kV}$ was calculated with the value of 3.3 years. The difference between two lifetime limit stems from the different stress application. In case of elongation rate, thermal stress was only applied to the specimens. On the contrary, in cases of AC breakdown, mechanical stress such as bending or impact at the low temperature was added to the thermally aged specimens. Therefore, about one third value in the lifetime of $19 \mathrm{kV}$ AC breakdown compared with the lifetime limit for $150 \%$ elongation rates was due to the thermally and mechanically multiple stresses.

Lifetime limit of 3.3 years seems to be very short. But, this is the case that the cable operates continuously at maximum permissible temperature of $70^{\circ} \mathrm{C}$. In other words, it means that a portable electric machine runs continuously for 3.3 years, which is not an actual situation. However, it is not easy to consider real operation pattern of the machine. Therefore, in this paper, lower operating temperature was assumed to estimate the practical lifetime of the cable.

If it is assumed that the cable operates continuously at $50^{\circ} \mathrm{C}$, the thermal lifetime would be considered to be 26.9 years whereas the lifetime limit with thermal and mechanical stress would be obtained to be just 9.9 years as

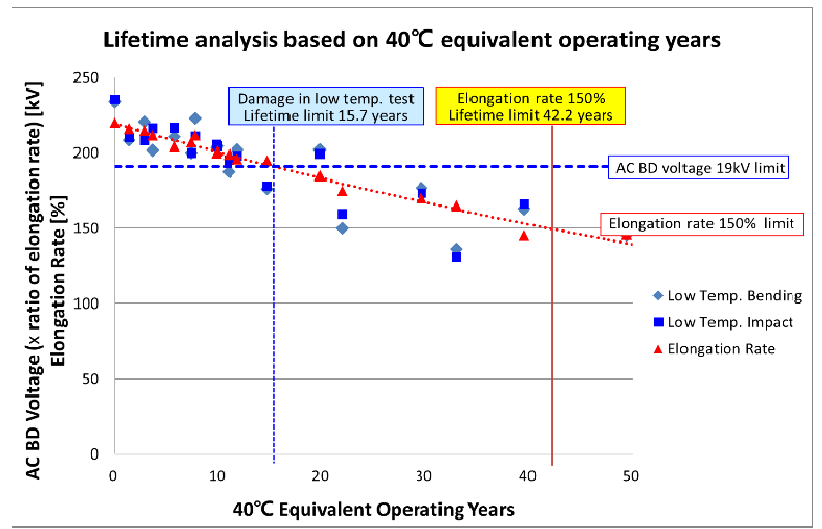

Fig. 9. Analysis of lifetime limit for $40^{\circ} \mathrm{C}$ equivalent operating years

shown in Fig. 8. Similarly, in the assumption of $40^{\circ} \mathrm{C}$ operation as shown in Fig. 9, the thermal lifetime would be 42.2 years whereas the lifetime limit with thermal and mechanical stress would be obtained to be 15.7 years. These considerations seem to be more practical for the use of portable electric machines. But, it is recommended to check damages in the cable insulation carefully during the use of the machines.

\section{Conclusion}

In this study, the lifetime of VCT cable mainly used in portable electric machines was analyzed through accelerated aging experiments with thermal, mechanical and electrical multiple-stresses and it is concluded as follows.

The elongation rate for degraded specimens was shown to be decreased exponentially with aging time and accelerated aging factors were calculated with aging temperatures based on the Arrhenius relationship. Through Weibull statistical analysis in the AC breakdown voltages for aged cables after low-temperature mechanical tests, it was analyzed that AC breakdown voltages were proportional to the elongation rates and $19 \mathrm{kV}$ of the scale parameter in Weibull analysis was suggested as limit value of lifetime.

Considering equivalent operating years at $70^{\circ} \mathrm{C}$ continuous operation for VCT cables, the thermal lifetime corresponding to elongation rate of $150 \%$ was 9.1 years, whereas the lifetime limit with thermal and mechanical stresses through AC breakdown assessment was calculated with 3.3 years. This difference would be due to the application of mechanical stress. In the assumption of $50^{\circ} \mathrm{C}$ and $40^{\circ} \mathrm{C}$ operation, the lifetime limit with thermal and mechanical stress would be obtained to be 9.9 years and 15.7 years respectively.

Based on the above analysis, it is possible to perform the lifetime assessment and degradation for low voltage cables 
using the analysis procedure and experiment with the thermal, mechanical and electrical multiple-stresses. However, it is most important to check damages in the cable insulation carefully during the use of the machines.

\section{Acknowledgements}

This work was supported by the Occupational Safety and Health Research Institute.

\section{References}

[1] David R. Lide, "Handbook of Chemistry and Physics", CRC Press, pp. 464-633, 1997

[2] "Electric disaster statistical analysis", Electrical Safety Corporation, No. 24, August 2015

[3] Vytenis Babrauskas, Ph.D., "Mechanisms and Modes for Ignition of Low-Voltage PVC Wires, Cables, and Cords", Fire \& Materials 2005, pp. 291-309, 2005

[4] Chung-Seog Choi, Kil-Mok Shong, Dong-Woo Kim, "Characteristics Analysis of Damaged Pattern by Repeated Stress of VCTFK", Journal of the Korean Society of Safety, 19(4), pp. 42-47, 2004 (in Korean)

[5] Kil-Mok Shong, Chung-Seog Choi, Dong-Woo Kim, Hee-Ro Kwak, "Analysis on the Characteristics of the Stranded Wire Disconnected by Bending Stress", KIEEME Summer Conference 2003, pp. 464-467, 2003 (in Korean)

[6] Lukasz Chmura et al, "Life curves for new and thermally aged oil-impregnated paper insulation", 2013 Electrical Insulation Conference, pp. 45-48, Ottawa, Ontario, Canada, 2-5 June, 2013

[7] KS C IEC 60811-1-2, "Thermal aging test method", 2012

[8] KS C IEC 60811-1-1, "Common test method of materials for insulation and sheath of electric cables Mechanical characteristic test", 2012

[9] H. P. Gasser et al, "Determining the aging parameter of cellulosic insulation in a transformer", High Voltage Engineering Symposium, No. 467, 4.143.P14.147.P1, 22-27 Aug., 1999

[10] Hyung-Ju Park et al, "Evaluation of Thermal Aging on PVC Using Thermo-Gravimetry Analysis and Accelerated Thermal Aging Test", Transactions of Korean institute of fire science and engineering, 18(3), pp.45-50, 2004

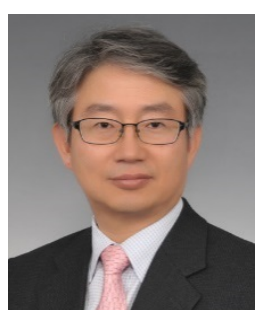

Jeongtae Kim $\mathrm{He}$ received B.S degree(1982), M.S degree(1987) and $\mathrm{Ph} . \mathrm{D}(1992)$ in electrical engineering from Hanyang university. He was a visiting professor of Mississippi State University from 2007 2008. Also, he was a Regular Member of CIGRE SCB1 (Insulated Cables) from 2000 2008 His main research fields are electrical insulation design and diagnosis for various electric equipments, especially partial discharge diagnostic technology.

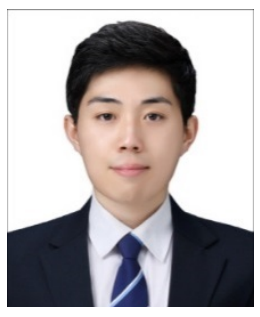

Ji-Sub Yoon He received his B.S. and M.S. degrees in Electrical Engineering from Daejin University, Pocheon, Korea in 2014 and 2016, respectively. His research interests include aging mechanisms, lifetime assessment and partial discharge measurement at different voltage conditions.

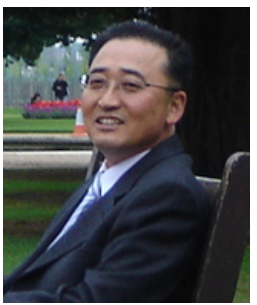

Sang-Won Choi He received the Ph.D. degree the Department of Electrical Engineering, Chungbuk National University, Republic of Korea, in 1999. He was affiliated Occupational Safety and Health Research Institute of the KOSHA(Korea Occupational Safety and Health Agency) as a researcher, a senior researcher, and he is affiliating as a director of Occupational Safety Research Bureau, from 1991 to at present. And he worked at Japan National Industrial Occupational Safety and Health as the fellower of Science and Technology Agency, Japan from 2001 to 2003. His current interests are electrical safety; electric shock, electrostatic discharge, electromagnetic interference. 